\title{
NOÇÃO DE ESPAÇO, LOCALIZAÇÃO E REPRESENTAÇÃO: REFLEXOS DA GEOGRAFIA ESCOLAR ${ }^{1}$.
}

\author{
Michele Batista Pereira ${ }^{2}$
}

A representação espacial é um dos eixos norteadores para a análise geográfica, sobretudo por permitir analises dos pontos de referência e signos que as pessoas estabelecem com o espaço assim como a relação que mantém com determinados espaços. Permite investigar ainda, que ideologias podem estar interferindo na representação espacial, qual é a percepção que se tem de determinados espaços, de que forma a proporção, a localização, orientação e as noções espaciais estão sendo registradas. O presente trabalho pretende verificar por meio de mapas mentais, entrevistas e leitura interpretativa de representação gráfica (mapa), de aproximadamente 20 pessoas (com idade a definir), como estas se relacionam, orientam, localizam e representam espaços próximos. $O$ estudo justifica-se pela observação empírica das dificuldades que algumas pessoas possuem para indicar pontos de referência, bem como se localizar, informar endereços, orientar-se nos espaços de vivência, mesmo após terem concluído a educação básica/formal. Pretende-se ainda estabelecer relação entre a noção de espaço, localização e representação de pessoas que possuem habilidade com o desenho e pessoas que não possuem essa habilidade, sobretudo por possivelmente vir a ser um obstáculo ao uso da representação enquanto objeto de análise, ou seja, a dificuldade de algumas pessoas em representar, podem causar insegurança. $O$ que nos leva às seguintes questões: Uma pessoa com habilidade para representar espaços através do desenho possui boas relações espaciais? Uma pessoa com boas noções espaciais consegue transpô-las corretamente para a representação gráfica? O ensino de Geografia escolar pode ser realmente útil à prática cotidiana? Questões estas que nos levam a questionar como está o ensino de Geografia nas escolas e quais habilidades estão sendo desenvolvidas. Afinal, a Geografia escolar proporciona habilidade que possam ser utilizada além dos portões da escola?

PALAVRAS-CHAVE: localização; orientação; noção de espaço.

\footnotetext{
${ }^{1}$ Orientadora: Prof. ${ }^{a}$ Dr. ${ }^{\text {a }}$ Salete Kozel Teixeira

${ }^{2}$ Mestranda em Geografia (UFPR) - e-mail: mibape@curitiba.org.br
} 